\title{
Synopsis of the Neotropical genus Jupoata Martins \& Monné, 2002 (Coleoptera: Cerambycidae)
}

\author{
Francisco Eriberto de Lima Nascimento ${ }^{1,2}$ \& Juan Pablo Botero ${ }^{1,3}$ \\ 1 Universidade de São Paulo (USP), Museu de Zoologia (MZUSP). São Paulo, SP, Brasil. \\ ${ }^{2}$ ORCID: 0000-0002-5047-8921. E-mail: eribnascimentofl@gmail.com \\ 3 ORCID: 0000-0002-5547-7987.E-mail: jp_bot@yahoo.com
}

\begin{abstract}
The genus Jupoata is redescribed and Jupoata antonkozlovi, a new species from Costa Rica is described. An updated key to species of the genus and a new geographical record are provided.
\end{abstract}

Key-Words. Central America; Cerambycina; morphology; Taxonomy.

\section{INTRODUCTION}

The genus Jupoata Martins \& Monné 2002 was established for some species previously included in Brasilianus Jakobson, 1924, which is currently a senior synonym of Hamaticherus AudinetServille, 1834. The species included in Brasilianus up to Martins \& Monné (2002) are currently distributed in six genera: Atiaia Martins \& Monné, 2002; Hamaticherus; Hirtobrasilianus, Fragoso \& Tavakilian, 1985; Juiaparus Martins \& Monné, 2002; Plocaederus Dejean, 1835; and Potiaxixa Martins \& Monné, 2002. Martins \& Monné (2002) discussed in detail these genera and their species. When studying the genus Brasilianus, Zajciw (1966) recognized five groups of species. The third group named "Plicatus" joined species with the $3^{\text {rd }}$ and $4^{\text {th }}$ antennomeres with spines perpendicular to antennal axis. Later, Martins (1979) substituted the name for "costalimai", since he concluded that Brasilianus plicatus (now Plocaederus plicatus (Olivier, 1790)) should have been allocated in the first group called "glabricollis". Finally, Martins \& Monné (2002) proposed the genus Jupoata for the species previously allocated in the "costalimai" group: J. garbei (Melzer, 1922); J. peruviana (Tippmann, 1960); J. rufipennis (Gory, 1831); and J. costalimai (Zajciw, 1966). They designated the last one as type species, and described three new species: J. gigas Martins \& Monné, 2002; J. paraensis Martins \& Monné, 2002; and J. robusta Martins \& Monné, 2002.

After that, some new species have been described from Central and South America: J. spinosa Martins \& Galileo, 2008, from French Guiana; J. divaricate Martins \& Galileo, 2011, from Bolivia; J. germana Martins, Galileo \& Limeira-de-Oliveira, 2011, from Brazil; J. brenesi Esteban-Durán \&
Martins, 2012 from Costa Rica; and J. jaechi Schmid, 2014, from Bolivia.

Esteban-Durán \& Martins (2012) provided the most recent key for identification of the species of Jupoata. Currently, the genus is composed of 12 species with geographical distribution for the following countries: Mexico, Honduras, Panama, Costa Rica, Peru, French Guiana, Suriname, Ecuador, Brazil, Bolivia and Argentina (Turnbow et al., 2003; Monné, 2017).

Herein, Jupoata is redescribed, a new species is described, and an updated key to species and a new geographical record are provided.

\section{MATERIAL AND METHODS}

Photographs were taken by Antonio SantosSilva (Museu de Zoologia, Universidade de São Paulo, São Paulo, Brazil - MZSP) using a Canon EOS Rebel T3i DSLR camera, Canon MP-E 65 mm f/2.8 1-5X macro lens, controlled by Zerene Stacker AutoMontage software. Measurements were taken in "mm" using measuring ocular Hensoldt/ Wetzlar - Mess 10 in the Leica MZ6 stereomicroscope, also used in the study of the specimens. The studied material is deposited at the MZSP.

\section{RESULTS}

\section{Jupoata Martins \& Monné, 2002}

Jupoata Martins \& Monné, 2002: 195; Monné, 2005: 54 (cat.); Monné, 2012: 11 (cat.); EstebanDurán \& Martins, 2012: 51 (key spp.); Monné, 2017: 45 (cat.). 
Type species: Brasilianus costalimai Zajciw, 1966 (original designation).

Redescription: Frons short, transverse. Antennal tubercles variable, usually acuminate at apex. Frontoclypeal suture deep with lateral fovea very deep. Eyes without setae between ommatidia; upper lobes of eyes with variable width; lower lobes well-developed. Antennae filiform, with variable length, in males from surpassing apex of elytra at antennomere VIII to twice length of body; in females from as long as body to slightly longer. Antennomere III with long straight apical spine, transverse to antennal axis, longer than antennomere IV; antennomere IV with apical spine from transverse to antennal axis to oblique with apex directed to apex of antennae; antennomere V with apical spine slightly shorter than IV, transverse or slightly directed to apex of antennae; antennomeres VI-X projected at apex; antennomere $\mathrm{XI}$ appendiculate.

Prothorax transverse, with two lateral projections, an antemedian tubercle, that can be slightly distinct or very projected, and another spine medially. Pronotum with transverse wrinkles, generally deep; procoxal cavities closed behind. Prosternal process truncate, with or without tubercle at apex. Mesoventral process lacking tubercle.

Elytra pubescent, parallel-sided, without costae; apices with both margins spined. Apices of meso- and metafemora spined or slightly projected.

Remarks: Among the genera of the subtribe Cerambycina (Cerambycini) with a rugose pronotum, Jupoata is the only one that has the antennomere III with an apical spine perpendicular to the antennal axis.

\section{Key to the species of Jupoata (modified and translated from Esteban-Durán \& Martins (2012))}

1. External spine of the antennomere IV perpendicular to antennal axis.

External spine of the antennomere IV oblique and directed toward apex of antennae. Brazil (Pará)...J. paraensis Martins \& Monné, 2002

2(1). Upper eye lobes with more than ten rows of ommatidia, separated each other by a distance equal to the width from two to five rows of ommatidia; humeri not projected forward

Upper eye lobes with about eight rows of ommatidia, separated each other by a distance equal to about the width of seven rows of ommatidia; humeri projected forward. Brazil (Rio de Janeiro, São Paulo, Paraná, Santa Catarina, Rio Grande do Sul), Bolivia (Santa (ruz), Paraguay ....................................... J. costalimai (Zajciw, 1966)

3(2). External elytral apex with short spine, shorter than or as long as pedicel length ................................................................................. 4

- External elytral apex with long spine, longer than pedicel ............... 8

4(3). Abdominal ventrites with pubescence not obscuring integument...5 Abdominal ventrites with pubescence obscuring integument. Bolivia (Chaparé) ... jaechi Schmid, 2014

5(4). Males with frons, scape, pedicel and antennomeres III-VIII without erect yellowish setae; metatibiae curved. In females, distance between upper eye lobes equal to width of three rows of ommatidia..
- Males with frons, scape, pedicel and antennomeres III-VIII with erect, yellowish setae; metatibiae straight. In females, distance between upper eye lobes equal to width of four rows of ommatidia. Brazil (Minas Gerais, São Paulo, Paraná, Santa Catarina, Rio Grande do Sul)... J. garbei (Melzer, 1922)

6(5). Pronotum with transverse wrinkles, straight and not fused; in males, distance between upper eye lobes equal to width of four or more rows of ommatidia.

- Pronotum with sinuous and irregular wrinkles partially fused; in males, distance between upper eye lobes equal to width of two rows of ommatidia. Costa Rica...J. brenesi Esteban-Durán \& Martins, 2012

7(6). Scape wide from base, shorter (about twice the greatest width of an upper (obe); external spine of antennomeres III and IV finer and longer........J. germana Martins, Galileo \& Limeira-de-Oliveira, 2011

- Scape narrowed at base, gradually widening toward apex, longer (about four times the greatest width of an upper lobe); external spine of antennomeres III and IV thicker and shorter.

J. robusta Martins \& Monné, 2002

8(3). Antennal spines long and thin; prosternal process with one or without distinct tubercle; antennae in males with twice the length of the body

- Antennal spines short and wide; prosternal process with two tubercles; antennae in males as long as three times the length of body. Peru, French Guiana .................. peruviana (Tippmann, 1960)

9(8). Elytra without black bands; pronotum with pubescence between wrinkles; elytra pubescent, with opaque aspect. 10

- Elytra with black bands close to suture and outer margin; pronotum without pubescence; elytra shining. French Guiana.

J. spinosa Martins \& Galileo, 2008

10(9). Vertex without wrinkles; lateral tubercle of prothorax long; elytral pubescence dense; external elytral spines parallel; prosternal process with tubercle.. 11

- Vertex with small transverse wrinkles; lateral tubercle of prothorax short; elytral pubescence sparse; external elytral spines divergent; prosternal process without distinct tubercle. Bolivia (Santa Cruz) .... .J. divaricata Martins \& Galileo, 2011

11(10). Pronotum with sub-straight wrinkles; scape and flagellomeres concolorous; metaventrite blackish; prosternal process with tubercle perpendicular to body axis

- $\quad$ Pronotum with markedly irregular wrinkles; antennomeres reddish orange, contrasting with color of the scape; metaventrite reddish; prosternal process with small tubercle with apex directed backward. Brazil (Amapá)... J. gigas Martins \& Monné, 2002

12(11). Scape widened at base and thinner toward apex; antennomere XI about as long as $2 / 3$ of elytral length. Costa Rica .......... . antonkozlovi sp. nov.

- Scape gradually widened toward apex; antennomere XI about as long as $1 / 3$ of elytral length. Mexico, Honduras, Nicaragua, Costa Rica, Panama, Trinidad and Tobago, Colombia, Venezuela, Ecuador, Peru, Bolivia (Cochabamba, La Paz, Santa Cruz), Suriname, Guyana, French Guiana, Brazil (Roraima, Amazonas, Pará, Mato Grosso, Goiás, Maranhão, Ceará, Pernambuco, Bahia, Minas Gerais, Espírito Santo, Rio de Janeiro, São Paulo, Paraná, Santa (atarina, Rio Grande do Sul), Paraguay, Argentina (Misiones), Uruguay...J. rufipennis (Gory, 1831)

\section{Jupoata antonkozlovi Nascimento \& Botero, new species} (Figs. 1-4, 6-7)

Description: Holotype male: Integument mostly dark brown; head, prothorax, meso- and metaventrite, legs, 
sides of humeri, epipleural margins and apex of elytra darker; antennomeres dark reddish brown, darker on apex; elytra reddish brown. General pubescence yellowish.

Head: Frons coarsely, confluently punctate; with short, sparse setae. Area between upper eye lobes glabrous; vertex abundantly punctate; median groove extending to level of area behind upper eye lobes; antennal tubercles abruptly elevated at apex, with vertical, glabrous groove at anterior region. Gulamentum finely, transversely carinate. Upper eye lobes with 11 rows of ommatidia, separated each other by distance equal to about width of two rows of ommatidia. Antennae as long as twice body length; reaching elytral apex at base of antennomere VIII. Scape robust, widened basally, narrowed toward apex, surface with coarse and irregular wrinkles; with short, sparse setae. Antennomeres III-VI slightly widened toward apex, with long spine perpendicular to axis
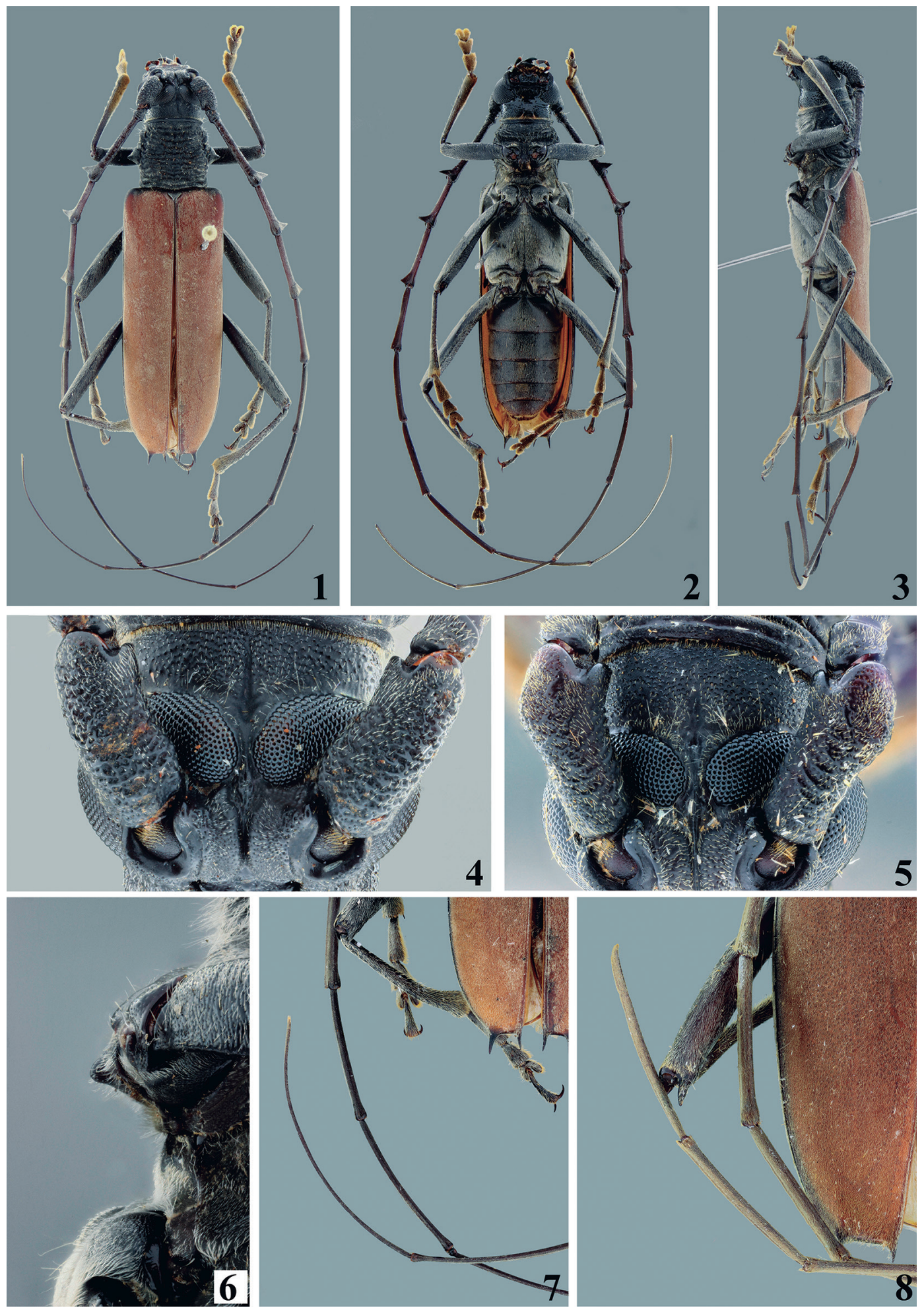

Figures 1-8. (1-4, 6-7), Jupoata antonkozlovi sp. nov., holotype, male. (1) Dorsal habitus. (2) Ventral habitus. (3) Lateral habitus. (4) Head, frontal view. (6) Detail of prosternal process in lateral view. (7) Detail of antennomere XI. (5, 8), Jupoata rufipennis. (5) Head, frontal view. (8) Detail of antennomere XI. 
of antennomere, about as long as width of antennomere; VII-X elongate; XI narrow, very long (about $2 / 3$ elytral length), curved. Antennal formula (ratio) based on length of antennomere III: scape $=0.5$; pedicel $=0.15$; IV $=0.75$; $\mathrm{V}=0.90 ; \mathrm{VI}=0.90 ; \mathrm{VII}=0.95 ; \mathrm{VIII}=1.00 ; \mathrm{IX}=1.20 ; \mathrm{X}=1.25$; $\mathrm{XI}=2.30$.

Thorax: Prothorax slightly wider than long; sides with distinct spine at middle area, and small tubercle at anterolateral region. Pronotum with abundant, transverse wrinkles, irregular in anterior half; with dense pubescence between wrinkles; with three gibbosities: two posterolateral, slightly elevated, and one elongate, more elevated at central area, V-shaped between lateral gibbosities. Prosternum with anterior half transversely sulcate; with moderately long, abundant setae, especially on basal half. Prosternal process abruptly elevated; apex with distinct perpendicular tubercle. Entire ventral area with abundant setae not obscuring integument.

Elytra: Surface with dense pubescence; apex obliquely truncate, bispinose, external spine as long as spine of antennomere III, innermost slightly shorter and curved.

Legs: Profemora with apex truncate; apex of mesofemora with raised internal flap, spine-shaped; metafemora with slightly raised internal flap in both sides of apex.

Dimensions (in $\mathrm{mm}$ ): Total length, 29.6; length of prothorax at center, 5.4; greatest width of prothorax, 6.9; anterior width of prothorax, 4.5; posterior width of prothorax, 5.0; humeral width, 7.4; elytral length, 21.9.

Type material: Holotype male from COSTA RICA, Alajuela: San Ramón (Bajo Los Rodríguez; 650 m), VII.2016, local collector (MZSP).

Etymology: The name is dedicated to Anton Olegovich Kozlov, who sent and donated the specimen.

Remarks: Jupoata antonkozlovi sp. nov. is similar to J. rufipennis by the general color of the body, form of the prothorax, and distinct tubercle of the prosternal process, which is perpendicular to the anteroposterior axis of the body. However, Jupoata antonkozlovi sp. nov. differs as follows: scape widened at base and thinner toward the apex (Fig. 4); antennomere XI about as long as $2 / 3$ of elytral length (Fig. 7). In Jupoata rufipennis, the scape (Fig. 5) is widened toward apex and the antennomere XI is as long as $1 / 3$ of elytral length (Fig. 8). Jupoata antonkozlovi sp. nov. is also similar to J. peruviana Tippmann, 1960 , by the shape of the scape, robust and widened at base, thinner toward the apex and by the antennomere $\mathrm{XI}$ about as long as $2 / 3$ of the elytral length. Martins \& Monné (2002) reported that according to the holotype photography of J. peruviana the scape is similar to that of the other species (thinner at base, widened toward the apex). Jupoata antonkozlovi sp. nov. differs from J. peru- viana by the total length of the antennae, which is twice the body length and by the prosternal process with one tubercle. In J. peruviana, the antennae have the triple of the body length and the prosternal process has two tubercles.

\section{New geographical record}

\section{Jupoata robusta Martins \& Monné, 2002}

Type locality: BRAZIL, São Paulo: Salesópolis (Estação Biológica de Boracéia). (MZSP).

It was described from Brazil (Maranhão, Pernambuco, Goiás, Minas Gerais, Rio de Janeiro, São Paulo (holotype), Paraná, and Santa Catarina). Currently, it is also known from the Brazilian state of Bahia (Monné, 2017).

Specimens examined: COSTA RICA, Limón (Near Guápiles town, $\left.10^{\circ} 10^{\prime} 5.880^{\prime \prime} \mathrm{N}, 83^{\circ} 46^{\prime} 44.400^{\prime \prime} \mathrm{W}\right), 2$ females, VI.2015, A. Kozlov col. (MZSP), new country record.

\section{ACKNOWLEDGMENTS}

We are very grateful to Anton Olegovich Kozlov, who provided the specimens for study and for donating it to the collection of MZSP. We also thank Antonio Santos-Silva (MZSP) for providing helpful comments on the manuscript. The First author thank the Fundação de Amparo à Pesquisa do Estado de São Paulo (FAPESP) for the scholarship Grant.

\section{REFERENCES}

Esteban-Durán, J.R. \& Martins, U.R. 2012. Jupoata (Coleoptera, Cerambycidae, (erambycinae): Nova espécie da Costa Rica e chave para identificação das espécies. Papéis Avulsos de Zoologia, 52(4): 51-53.

Martins, U.R. 1979. Notas e descrições em Brasilianus Jakobson, 1924 (Coleoptera, Cerambycidae). Revista Brasileira de Entomologia, 23: 23-28.

Martins, U.R. \& Monné, M.A. 2002. Tribo Cerambycini. pp. 145-248. In: Martins, U.R. (Ed.). Cerambycidae Sul-Americanos (Coleoptera), Taxonomia. São Paulo, Sociedade Brasileira de Entomologia. v. 4, 265p.

Monné, M.A. 2005. Catalogue of the Cerambycidae (Coleoptera) of the Neotropical Region. Part I. Subfamily Cerambycinae. Zootaxa, 946: 1-765.

Monné, M.A. 2012. Catalogue of the type-species of the genera of the Cerambycidae, Disteniidae, 0xypeltidae and Vesperidae (Coleoptera) of the Neotropical Region. Zootaxa, 3213: 1-183.

Monné, M.A. 2017. Catalogue of the Cerambycidae (Coleoptera) of the Neotropical Region. Part I. Subfamily Cerambycinae. Available at: http:// cerambyxcat.com/Parte1 Cerambycinae.pdf. Access in: 08/2017.

Turnbow, R.H.; Cave, R.D. \& Thomas, M.C. 2003. A list of the Cerambycidae of Honduras, with additions of previously unrecorded species. Ceiba, 44(1): $1-43$.

Zajciw, D. 1966. Estudos do gênero "Brasilianus" Jakobson, 1924 (Col., (erambycidae, (erambycinae). Revista Brasileira de Biologia, 26(1): 47-58. 